\title{
Developmental Alterations and Osmoregulatory Physiology of a Larval Anuran under Osmotic Stress
}

\author{
I. Gomez-Mestre ${ }^{1, *}$ \\ M. Tejedo ${ }^{1}$ \\ E. Ramayo ${ }^{2}$ \\ J. Estepa ${ }^{2}$
}

${ }^{1}$ Departamento de Biología Evolutiva, Estación Biológica de Doñana, CSIC, Avda. Maria Luisa s/n, Pabellón de Perú, 41013 Sevilla, Spain; ${ }^{2}$ Servicio de Análisis Clínicos, Hospital de Valme. Crta. Cádiz s/n, Sevilla, Spain

\begin{abstract}
Water salinity represents an environmental stress for many species. Amphibians are particularly sensitive because they are generally poor osmoregulators, and most species are completely absent from brackish and saline environments. We experimentally examined the effect of different salinity levels on larvae of the toad Bufo calamita L., a species that occupies freshwater ponds but can also breed in brackish ponds. Two independent experiments are reported here. In both experiments, tadpoles under saline conditions (ranging between 85 and 200 mOsm) showed a slower developmental rate, metamorphosing between 4 and $9 \mathrm{~d}$ later than the controls. Bufo calamita tadpoles reared in brackish water increased their osmolality and solute concentration (mainly sodium and chloride), decreased their levels of glucose, and decreased the total protein content, all measured from whole-animal extracts. Although most larval anurans are strictly ammoniotelic until the completion of metamorphosis, a few species exposed to dehydrating environments have evolved the ability to use urea as an osmolyte during the larval phase. The data presented here reveal that although $B$. calamita seems to be yet another exception to the rule of larval strict ammoniotelism, the tadpoles are not able to use urea as an osmolyte and rely on sodium-chloride balance instead. Preliminary immunoassays of thyroid hormone content suggest a possible decrease in hormone levels induced in water salinity conditions that correlate with a decreased developmental rate.
\end{abstract}

\footnotetext{
* Corresponding author. Present address: Department of Biology, Boston University, 5 Cummington Street, Boston, Massachusetts 02215; e-mail: igmestre@ bu.edu.
}

Physiological and Biochemical Zoology 77(2):267-274. 2004. (C) 2004 by The University of Chicago. All rights reserved. 1522-2152/2004/7702-2078\$15.00

\section{Introduction}

Environmental stress is generally understood as any environmental factor that reduces the fitness of an organism (Koehn and Bayne 1989; Hoffmann and Parsons 1991). Among the vertebrates, amphibians are particularly sensitive to environmental stresses. Low food levels, extreme temperature, and low $\mathrm{pH}$ clearly affect the development and fitness of larval anurans (see Ultsch et al. 1999 for a review). Water salinity is a stressor that has been less studied to date, although it is likely to be important, since most amphibians avoid brackish waters. Although amphibians are generally restricted to freshwater during their embryonic and larval phases, adult amphibians capable of withstanding dehydrating environments have been reported for both arid and hypersaline media (Neill 1958; Shoemaker and Nagy 1977; Balinsky 1981; Katz 1989), where they experience an acute increase in their osmotic concentration. Such increase is caused by urine retention, accumulation of electrolytes, and enhanced urea synthesis (Gordon 1962; McBean and Goldstein 1970). In contrast, larvae and aquatic adult forms tend to be ammoniotelic, with the exception of a few specialized species (Katz 1989), and do not use urea as an osmolyte. Little research has examined osmoregulation and the ecological implications of osmotic stress on tadpoles, although they are likely to be more severely affected by water salinity than adults (Boutilier et al. 1992). Here we report two experiments addressing the physiological changes experienced by larvae of a bufonid toad after saline exposure.

Bufo calamita is a common species throughout continental Spain (Tejedo and Reques 1997). It typically breeds in freshwater temporary ponds but can also be found in inland brackish lagoons and coastal marshes and has been considered tolerant of brackish water (Neill 1958; Balinsky 1981; Sinsch et al. 1992; Gomez-Mestre and Tejedo 2002). Osmotic stress may be especially acute for B. calamita larvae because they occur in temporary water bodies, and as the water evaporates, the salinity concentration quickly increases.

The first experiment assessed the effect of water salinity on larval survival, developmental rate, and growth rate, as well as the physiological adjustments accompanying saline immersion, specifically, concentrations of main electrolytes, nitrogen waste, and general body condition. A second experiment was performed to test the hypothesis that the decreased developmental 
rate is related to changes in active thyroid hormone levels. Thyroid hormone is the main endocrine trigger of metamorphosis in amphibians (White and Nicoll 1981; Denver 1996; Kaltenbach 1996). We measured thyroid hormone levels in stage-matched tadpoles exposed to different water salinities. Bufo calamita populations in southern Spain show geographic variation in their tolerance to water salinity so that populations from brackish ponds suffer less acute developmental alterations than freshwater populations when exposed to osmotic stress (Gomez-Mestre and Tejedo 2003). For this reason, two different populations were included in the second experiment, one from a brackish pond and the other from a freshwater pond.

We tested the following hypotheses: (1) water salinity constitutes an abiotic stress to larvae of $B$. calamita and reduces their fitness, as measured by survival, developmental rate, and/ or growth rate; (2) B. calamita larvae have to cope with increased ambient osmolarity by withstanding a rise in internal electrolyte concentration because they are unable to synthesize urea; (3) effects of salinity on tadpole developmental rate are mediated by stage-specific alterations in thyroid hormone concentrations; (4) the population native to brackish ponds will show higher survival, developmental rate, and growth than the population native to freshwater ponds.

\section{Material and Methods}

\section{Experiment 1: Effect of Salinity on Development and Physiology}

Eleven Bufo calamita clutches were sampled on March 1999 from a freshwater temporary pond located at the Sierra Norte de Sevilla in southern Spain. The water in this locality has a salinity range of $0.20-0.28 \mathrm{~g} / \mathrm{L}$ and is slightly bicarbonated $(2.16$ meq), with low levels of sodium and chloride $(0.45$ meq and 1.5 meq, respectively). Small portions of each clutch were collected, pooled together, and kept in well-aerated freshwater at $21.5^{\circ}-24.5^{\circ} \mathrm{C}$ until Gosner stage 25 (Gosner 1960). Three salinity treatments were established: freshwater (4 mOsm), salt 1 (85 mOsm), and salt 2 (140 mOsm). Freshwater consisted of a mixture of dechlorinated tap water and natural pond water. Brackish water was taken from a B. calamita breeding pond, stored, and diluted with freshwater until the desired concentrations were reached. Water salinity was measured with a conductivity meter (Model CDH-46, Omega Engineering). All salinities used throughout the study are well within the range measured in natural ponds where B. calamita breed (M. Tejedo and I. Gomez-Mestre, personal observation). The $\mathrm{pH}$ ranged from 7.40 to 7.59 and did not differ significantly among treatments. Randomly chosen larvae were placed individually in plastic cups filled with $500 \mathrm{~mL}$ of water and arranged in a randomized block design with eight blocks, each block containing seven replicates of each of the three experimental salinity levels, yielding a total of 56 replicates per treatment. Water was renewed and larvae were fed $30 \mathrm{mg}$ of ground rabbit chow per tadpole twice weekly. Response variables were larval survival, length of the larval period (until forelimb emergence, Gosner stage 42), and size at metamorphosis (at tail resorption, Gosner stage 46$)$.

For the biochemical analysis, one-half of the replicates from each treatment were preserved $20 \mathrm{~d}$ after the beginning of the experiment. Developmental stage was assessed, and tadpoles were weighed and frozen. Then $300 \mathrm{~mL}$ of distilled and deionized water were added to each tube, and samples were homogenized with an electric mechanical homogenizer (Ultra Turrax, IKA-Labortechnik). Whole-body determinations were necessary in this and the next experiment, due to the small size of bufonid tadpoles (Weber et al. 1994; Gancedo et al. 1997; Ultsch et al. 1999). Tubes were then centrifuged at 7,000 $\mathrm{g}$ for 20 min. All parameters were determined from the supernatant, except for total protein, which was measured from the pellet, after resuspension in another $300 \mathrm{~mL}$ of $\mathrm{NaOH} 0.1 \mathrm{~N}$. Osmolality was measured using a Micro Osmometer (Advanced Instruments). The electrolytes sodium, chloride, and potassium were determined using an EL-ISE analyzer (Beckman); ammonia was assayed using a COBAS Integra analyzer (Roche, Alemania); and the remaining parameters were analyzed using a Clinical Chemistry Analyzer Hitachi 747 (Model 100, Hitachi). All reagents used in the analyses were Roche standards. The specific techniques employed by the instruments above are listed in Table 1.

\section{Experiment 2: Effect of Salinity on Endocrine Control of} Metamorphosis

New water salinity treatments were established, increasing the concentrations of the two brackish treatments with respect to experiment 1 in order to accentuate the differences among treatments. The concentrations were fresh (4 mOsm), 140 mOsm, and 200 mOsm, prepared as described for experiment 1. The larvae were collected in April 2000 from two B. calamita populations, one from freshwater ponds (Sierra Morena, six clutches) and the other from a brackish pond (Laguna de los Jarales, nine clutches), both in Córdoba province, southwestern Spain. When the animals reached Gosner stage 25, they were individually reared in plastic cups as in experiment 1 . Because hormone concentrations are strongly dependent on developmental stage (Gatten et al. 1992; Denver 1996; Kaltenbach 1996), a stage-matched comparison was required. Animals were blotted dry, weighed, and frozen at either Gosner stage 38 (premetamorphosis), Gosner stage 42 (forelimb emergence), or Gosner stage 46 (tail resorption), regardless of their age. The design was complete factorial, with three salinity levels (4, 140, and 200 mOsm), two populations (fresh and brackish origins), and three developmental stages. It was replicated six times and arranged in six randomized blocks. Samples were immersed in liquid nitrogen for a few seconds. Then, two small steel balls were inserted in the tube, and the sample was placed on a 
Table 1: Adjusted means and standard errors of the biochemical parameters estimated in Bufo calamita tadpoles exposed to different salinity levels (fresh, 85, and 140 mOsm)

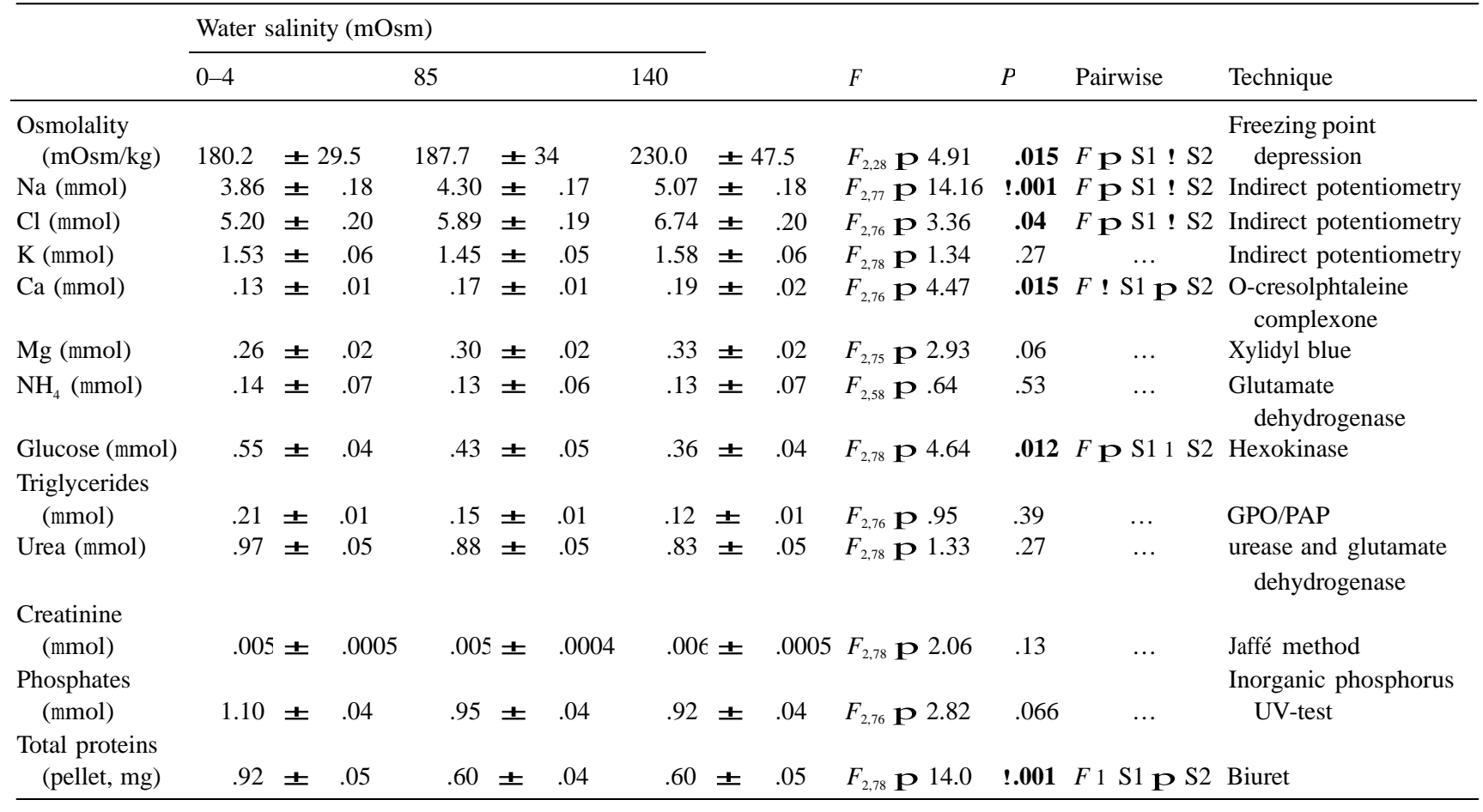

Note. The effect of water salinity on each parameter was tested using the wet weight of the tadpole as covariate. Significant $P$ values $(P ! 0.05)$ are in bold. The column labeled "pairwise" reflects the output of pairwise comparisons between treatments. Significance levels were corrected using a Sidak multiple comparison adjustment, and an equal sign denotes lack of statistical significance. Uric acid, cholesterol, and bilirubin were absent in the samples or below the detection limits and thus are not included in the table.

Mixer Mill 200 (Retsch, Germany) until the sample was homogeneously pulverized. Then $300 \mathrm{~mL}$ of miliQ water were added to each sample, vortexed, and then centrifuged $10 \mathrm{~min}$ at 3,000 rpm. Whole-body thyroid hormone determinations of both thyroxine $\left(\mathrm{T}_{4}\right)$ and triiodothyronine $\left(\mathrm{T}_{3}\right)$ were done on the supernatant by ECLIA (electrochemiluminiscence immunoassay) using a ELECSYS 2010 (Roche).

\section{Data Analysis}

Data were analyzed fitting generalized linear models by means of the SAS package (SAS Institute 1999), using the GENMOD procedure for survival data and the MIXED procedure for length of the larval period, size at metamorphosis, growth rate, and biochemical parameters. Nonparametric tests were used to look for differences in developmental stage among treatments. Variables were $\log _{\mathrm{e}}$ transformed when necessary in order to reduce heteroscedasticity. Analyses of biochemical parameters included corrections for body mass differences using larval wet weight as a covariate. A Bonferroni adjustment of the significance level was applied for the analysis of biochemical parameters.

\section{Results}

Experiment 1: Effect of Salinity on Development and Physiology

Survivorship did not differ across treatments. However, water salinity caused a retardation in the development of Bufo calamita tadpoles. By day 20, tadpoles in the freshwater treatment were significantly more developed than those in brackish water treatments (Kruskal-Wallis $H \mathbf{P} 35.85, N \mathbf{P} 86, P$ ! 0.001; see Fig. 1). No significant differences between the two saline treatments were found. Tadpole wet weight at day 20 also decreased significantly as salinity increased $\left(F_{2,79} \mathbf{P} 4.56, P\right.$ P 0.013), although it may have been associated with variation in the developmental stage. Tadpoles took significantly longer to reach metamorphosis when reared in brackish water $\left(F_{2,23} \mathbf{P} 30.42\right.$, $P$ ! 0.001). The average delay compared with the freshwater control was 6 and $9 \mathrm{~d}$ for the 85 mOsm and 140 mOsm treatments, respectively (Fig. 2A). No significant differences between the two saline treatments were found. Tadpole weight at metamorphosis did not differ significantly across treatments and, therefore, the growth rate was higher in freshwater conditions $\left(F_{2,23} \mathbf{P} 11.19, P\right.$ ! 0.001).

Many physiological parameters differed among salinity treatments (Table 1). Water osmolality was below the levels mea- 


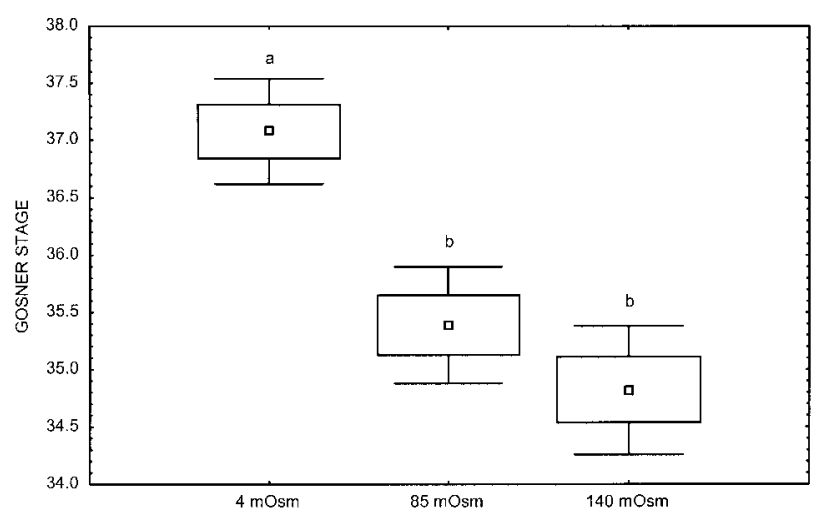

Figure 1. Developmental stage (sensu Gosner 1960) of Bufo calamita tadpoles after $20 \mathrm{~d}$ in different salinity treatments (boxes $\pm 1 \mathrm{SE}$; error bars $\pm 1 \mathrm{SD}$ ). Tadpoles between standard stages were scored in halfstages. After $20 \mathrm{~d}$, tadpoles reared in freshwater were significantly more developed than those exposed to saline water (Kruskal-Wallis; treatments labeled with different letters are statistically different at $P$ ! $0.05)$.

sured in the tadpole samples in all cases. Osmolality of the tadpoles differed significantly among treatments; tadpoles in 140 mOsm showed significantly higher osmolality than those in the other two treatments. Differences were also observed in $\mathrm{Na}^{+}, \mathrm{Cl}^{-}$, and $\mathrm{Ca}^{2+}$, while differences in $\mathrm{Mg}^{2+}$ were marginally nonsignificant (see Table 1). Similar levels of urea and ammonia were found across treatments, while uric acid was undetectable. Creatinine levels were almost negligible, and bilirubin could not be detected.

Tadpoles lacked cholesterol but had a considerable amount of triglycerides, though they were unaffected by the salinity treatments. Phosphates did not vary significantly. Glucose levels differed significantly among treatments and were higher for those reared in freshwater. The same was true for the total amount of proteins derived from the pellet. No proteins were detected in the supernatant.

\section{Experiment 2: Effect of Salinity on Thyroid Hormone Levels}

Water salinity again showed no effect either on survival or on weight at metamorphosis. It significantly affected the duration of the larval period ( $F_{2,88} \mathbf{P} 32.15, P$ ! 0.0001), delaying metamorphosis with respect to freshwater controls (22\% and $27 \%$ delays for the $6 \mathrm{~g} / \mathrm{L}$ and $8 \mathrm{~g} / \mathrm{L}$ treatments, respectively; see Fig. $2 B$ ). Neither population of origin nor its interaction with water salinity significantly affected growth or developmental rate.

Thyroxine $\left(\mathrm{T}_{4}\right)$ concentration was higher in individuals at Gosner stage 38 and decreased in later stages. Triiodothyronine $\left(\mathrm{T}_{3}\right)$ showed less variable concentrations across developmental stages, increasing at stage 42 (see Fig. 3). At stage 38, $\mathrm{T}_{4}$ concentration was significantly lower in the freshwater treatment than in brackish water tadpoles $\left(F_{2,35} \mathbf{P} 3.87, P \mathbf{P} 0.0304\right) . \mathrm{T}_{3}$ showed the reverse pattern and was higher in the freshwater treatment $\left(F_{2,33} \mathbf{P} 3.15, P \mathbf{P} 0.055\right)$. A contrast analysis between fresh and 200 mOsm treatments confirmed these differences $\left(F_{1,33} \mathbf{P}\right.$ 6.19, $\left.P \mathbf{P} 0.018\right)$. At stage 42 the situation was similar: $\mathrm{T}_{4}$ was higher in the brackish treatments $\left(F_{2,33} \mathbf{P}\right.$ 5.46, $P$ ! 0.01), and $\mathrm{T}_{3}$ was higher in the freshwater treatment $\left(F_{2,32} \mathbf{P}\right.$ 2.92, P $\mathbf{P} 0.068$; contrast fresh vs. $200 \mathrm{mOsm}$ : $F_{1,32} \mathbf{P}$ 5.33, $P$ P 0.028). No significant differences were found in hormone level across treatments at stage 46 .

\section{Discussion}

Osmoregulatory Physiology

Tadpoles maintained an internal osmolality approximately 100 mOsm hyperosmotic to the water, matching the situation described by Hoffman and Katz (1997) for Bufo viridis adults.
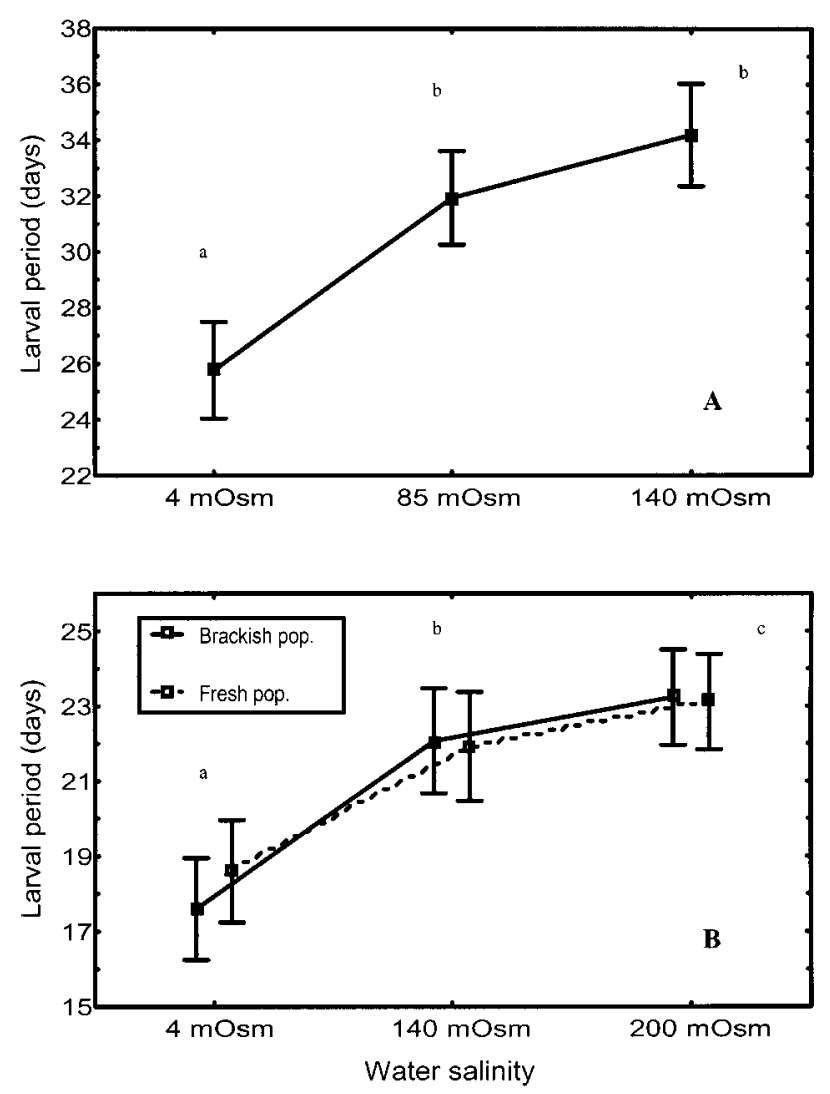

Figure 2. Effect of water salinity on larval period of Bufo calamita. Data are mean ( \pm SE) number of days from Gosner stage 25 to forelimb emergence (Gosner stage 42). A, Results from experiment 1. Tadpoles reared in saline water significantly delayed metamorphosis with respect to the freshwater control. B, Results from experiment 2 . Again, water salinity induced delayed metamorphosis. No differences were detected between native and nonnative populations to brackish environments. Salinity treatments with values labeled with different letters are statistically different at $P ! 0.05$. 


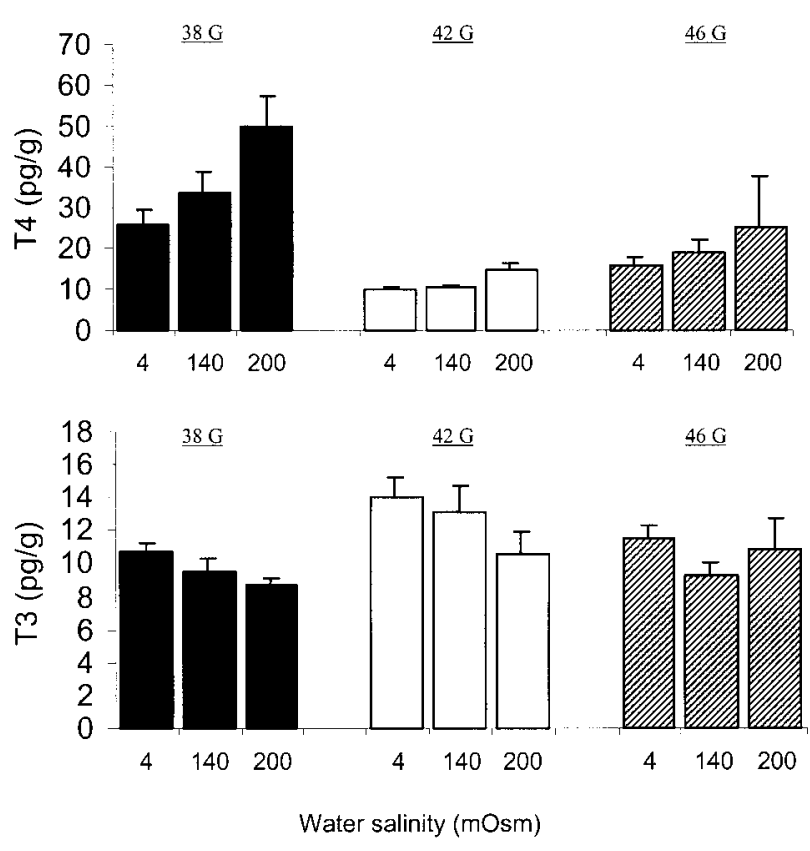

Figure 3. Thyroxine $\left(\mathrm{T}_{4}\right)$ and triiodothyronine $\left(\mathrm{T}_{3}\right)$ concentrations determined in whole-body homogenates from Bufo calamita tadpoles raised in three water salinity treatments. Solid bars indicate tadpoles analyzed at Gosner stage 38, empty bars indicate tadpoles analyzed at Gosner stage 42, and hatched bars indicate tadpoles analyzed at Gosner stage 46 . Data are means $+1 \mathrm{SE}$.

From the few reports available on tadpole osmoregulation, apparently only Limnonectes cancrivorus ( $\mathbf{P}$ Rana cancrivora) larvae can regulate internal osmolality below that of the environment (see Shoemaker et al. 1992 for a review). Bufo calamita would belong to the group of salinity-acclimable species (Balinsky 1981; Sinsch et al. 1992) that nevertheless cannot remain hyposmotic to the brackish environment. High tolerance of osmotic stress in adult amphibians (including B. calamita) is based on the accumulation of metabolites, especially urea, after an initial increase in sodium and chloride (Shpun et al. 1992; Hoffman and Katz 1997). The increase in osmolality observed in the tadpoles was almost exclusively due to the increase in sodium and chloride concentrations, and urea was not accumulated even though it was produced. Urea content in all treatments was remarkably higher than expected for anuran tadpoles, which are generally considered to be ammoniotelic. The urea cycle is thought to be poorly active in tadpoles because thyroid hormone is needed to activate it during metamorphic climax (Balinsky 1970; Balinsky et al. 1972; Wright and Wright 1996). Only anuran larvae of species showing an unusually fast development such as Scaphiopus couchi and Spea multiplicata (Buchholz and Hayes 2002) were thought to be capable of producing urea during the larval phase (Jones 1980). Bufo calamita tadpoles generated both ammonia and urea. Because ammonia is highly toxic and must be quickly excreted to the water, the results obtained are likely underestimating its production. It is unclear why, even if B. calamita is apparently an exception to the rule of larval ammoniotelism, urea was not being accumulated under brackish conditions to relieve the effects of hypernatremia, as adults do.

Increased sodium and chloride content was probably due to passive absorption of the electrolytes. Bufo calamita tadpoles increase their water content as salinity rises, until the environmental osmolality reaches around $90 \mathrm{mOsm}$, decreasing it thereafter (I. Gomez-Mestre and M. Tejedo, unpublished data). Potassium concentration, responsible for the cytoplasmic osmotic pressure, remained at an almost constant concentration, being excluded from osmoregulatory compensation. The firm regulation of potassium concentration found here is consistent with some other studies (Garland and Henderson 1975; Degani et al. 1983; Shpun et al. 1992; Shpun and Katz 1999), although it might not be universal (Degani and Warburg 1984). The observed calcium increase with water salinity was unexpected from an osmoregulatory perspective, but Stengel and Hanke (1990) described the calcium exchange system of tadpoles as an open system that enables a more or less continuous uptake by the skin. There is no straightforward physiological interpretation of this result, especially since calcium is likely to be stored in particular regions of the body and remain there until bone formation after metamorphosis. Because we were forced to homogenize the tadpoles, we may be measuring calcium not yet physiologically available. Uchiyama et al. (1990) found calcium to be closely regulated in $L$. cancrivorus serum.

Animals raised in freshwater had significantly higher levels of glucose and total proteins, suggesting a better general body condition than that of tadpoles under osmotic stress. Higher levels of glucose and proteins may be explained either because of a higher metabolic rate in freshwater (nonstressful) versus brackish conditions (Plaut 2000) or because of a distinct allocation of the energy expenses. It is possible that tadpoles under osmotic stress expend a larger proportion of their energy in osmoregulatory tasks. Kirschner et al. (1971) estimated that ionic regulation accounted for at least $3 \%$ of the total energy turnover and perhaps considerably more. Katz detected changes in the rate of oxygen consumption of Bufo viridis (Katz 1973) and Rana ridibunda (Katz 1975) when they were transferred to high salinities, but not if they were gradually acclimated. Ionic exchange in tadpoles takes place mainly through the gills (Shoemaker and Nagy 1977), and to a lesser extent through the skin (though an ontogenetic gill-to-skin shift has been detected; Zamorano and Salibián 1994; Ultsch et al. 1999). Consistent with the increased ionic exchange rate expected at higher salinities, Uchiyama and Yoshizawa (1992) found a higher turnover of polymorphic mitochondria-rich cells of the gills in $L$. cancrivorus tadpoles as compared with their freshwater controls. Further experiments focused on the metabolic rate under different osmotic conditions are required to shed light on this point. 


\section{Developmental Retardation}

Brackish water decreased both developmental and growth rates of $B$. calamita tadpoles, although it had no effect on larval survival. Given the temporary character of the breeding sites of this species, tadpoles growing in brackish ponds face a twofold challenge: drying of the pond and increasing osmotic stress. This environment imposes selection for the completion of metamorphosis as soon as possible in order to evade the deteriorating environment. However, our results consistently showed that tadpoles raised in saline water took longer to metamorphose, as suggested by Gordon and Tucker (1965) and also as shown by Christy and Dickman (2002). Delaying metamorphosis clearly reduces fitness both through an increased risk of desiccation and through physiological failure due to the acute increase in osmotic stress in evaporating ponds. There was no evidence for higher salinity tolerance in the Jarales population from a brackish environment, lending no support to the hypothesis of local adaptation, even if adaptive divergence in developmental rates under salinity conditions has been shown for these same populations in other experiments (GomezMestre 2002). Delayed metamorphosis due to water salinity might reflect a nonadaptive alteration in the stage-specific levels of active thyroid hormone (TH). TH concentrations estimated in this study are approximately tenfold less than those estimated in other studies carried out on the same species (Gancedo et al. 1997) or on other bufonids (Niinuma et al. 1991; Weber et al. 1994), probably due to the absence of hormone extraction in our procedure. Most of the TH is likely to have been tissue bounded, and thus only circulating hormones would have been measurable. This precludes straightforward comparison of the absolute values obtained here with previous studies. However, internal comparison across treatments within this study remains valid but should only be considered preliminary. Thyroxine $\left(\mathrm{T}_{4}\right)$ is the precursor of the active form triiodothyronine $\left(T_{3}\right)$. Lower $T_{4}$ concentrations found in tadpoles in freshwater suggest that the conversion to $\mathrm{T}_{3}$ was greater. Accordingly, in stage-matched comparisons, $\mathrm{T}_{3}$ concentration was higher under freshwater conditions (see Fig. 3). We propose two possible mechanisms of salinity-induced decrease in thyroid hormone levels worth further research. First, the production of prolactin could be increased under saline conditions and antagonize the thyroid hormone. Prolactin is known to antagonize the thyroid hormone effect on growth and metamorphosis of tadpoles (White and Nicoll 1981; Denver 1996; Shi 2000), but it also antagonizes the thyroid stimulation of sodium and water uptake (Brown and Brown 1973). Second, glucocorticoids such as corticosterone are under the same pituitary control as mineralocorticoids, which in turn are important in osmoregulation. Corticosterone has been shown to delay metamorphosis when increased during early development in Bufo boreas (Hayes 1995; Hayes and Wu 1995) and could be up-regulated under saline conditions.
In summary, B. calamita tadpoles exposed to moderate water salinity experienced reduced developmental rate (presumably by reducing active $\mathrm{TH}$ concentrations), increased osmolality through sodium and chloride contents, and decreased levels of glucose and total proteins. Unlike most anuran larvae, B. calamita was capable of producing urea before the onset of metamorphosis but did not use it as an osmolite during the larval phase. The alteration in the developmental rate did not affect final body mass of the metamorphs but substantially delayed metamorphosis, increasing the risk of desiccation and exposure of the tadpoles to acute increases in osmotic stress.

\section{Acknowledgments}

We are grateful to Uri Katz for advice during the whole project and for reviewing earlier drafts of this article. Tyrone B. Hayes hosted I.G.-M. in his lab during a short stage and, together with Daniel Buchholz, discussed thoroughly and helpfully the endocrine basis of the developmental retardation caused by salinity. Adolfo Marco, Pilar Herrero, Daniel Buchholz, and Karen Warkentin reviewed earlier versions of the manuscript and provided useful comments that helped improve it. We acknowledge Carmen Díaz, Ana Pardo, and Reyes Velasco for their assistance in processing the samples at the Hospital Universitario de Valme. This work was supported by grant PB960861 from Dirección General de Investigación Científica y Técnica (DGICYT) conceded to M.T. and predoctoral grant AP97-05421411 from the Dirección General de Enseñanza Superior e Investigación Científica to I.G.-M. We also thank the Consejería de Medio Ambiente de la Junta de Andalucía and Delegación Provincial de Córdoba for providing the corresponding permits.

\section{Literature Cited}

Balinsky J.B. 1970. Nitrogen metabolism in amphibians. Pp. 519-637 in J.W. Campbell, ed. Comparative Biochemistry of Nitrogen Metabolism. 2. The Vertebrates. Academic Press, London.

. 1981. Adaptation of nitrogen metabolism to hypertonic environment in Amphibia. J Exp Zool 215:335-350.

Balinsky J.B., T.L. Coetzer, and F.J. Mattheyse. 1972. The effect of thyroxine and hypertonic environment on the enzymes of the urea cycle in Xenopus laevis. Comp Biochem Physiol 43B:83-95.

Boutilier R.G., D.F. Stiffler, and D.P. Toews. 1992. Exchange of respiratory gases, ions, and water in amphibious and aquatic amphibians. Pp. 81-124 in M.E. Feder and W.W. Burggren, eds. Environmental Physiology of the Amphibians. University of Chicago Press, Chicago.

Brown P.S. and S.C. Brown. 1973. Prolactin and thyroid hormone interactions in salt and water balance in the newt 
Notophthalmus viridescens. Gen Comp Endocrinol 20:456466.

Buchholz D.R. and T.B. Hayes. 2002. Evolutionary patterns of diversity in spadefoot toad metamorphosis (Anura: Pelobatidae). Copeia 102:180-189.

Christy M.T. and C.R. Dickman. 2002. Effects of salinity on tadpoles of the green and golden bell frog (Litoria aurea). Amphibia-Reptilia 23:1-11.

Degani G., S. Goldenberg, and M.R. Warburg. 1983. Changes in ion, urea concentrations and blood plasma osmolarity of Pelobates syriacus juveniles under varying conditions. Comp Biochem Physiol 75A:619-623.

Degani G. and M.R. Warburg. 1984. Changes in concentrations of ions and urea in both plasma and muscle tissue in a dehydrated hylid anuran. Comp Biochem Physiol 77A:357360.

Denver R.J. 1996. Neuroendocrine control of amphibian metamorphosis. Pp. 433-464 in L.I. Gilbert, J.R. Tata, and B.G. Atkinson, eds. Metamorphosis: Postembryonic Reprogramming of Gene Expression in Amphibian and Insect Cells. Academic Press, San Diego, Calif.

Gancedo B., A.L. Alonso-Gómez, N. de Pedro, M.J. Delgado, and M. Alonso-Bedate. 1997. Changes in thyroid hormone concentrations and total contents through ontogeny in three anuran species: evidence for daily cycles. Gen Comp Endocrinol 107:240-250.

Garland H.O. and I.W. Henderson. 1975. Influence of environmental salinity on renal and adrenocortical function in the toad, Bufo marinus. Gen Comp Endocrinol 27:136-143.

Gatten R.E., K. Miller, and R.J. Bull. 1992. Energetics at rest and during locomotion. Pp. 314-377 in M.E. Feder and W.W. Burggren, eds. Environmental Physiology of the Amphibians. University of Chicago Press, Chicago.

Gomez-Mestre I. 2002. Variación Geográfica y Adaptación Local al Estrés Osmótico en el Sapo Corredor, Bufo calamita. Ph.D. thesis, Universidad de Sevilla, Spain.

Gomez-Mestre I. and M. Tejedo. 2002. Geographic variation in asymmetric competition: a case study with two larval anuran species. Ecology 83:2102-2111.

2003. Local adaptation of an anuran amphibian to osmotically stressful environments. Evolution 57:1889-1899.

Gordon M.S. 1962. Osmotic regulation in the green toad (Bufo viridis). J Exp Biol 39:261-270.

Gordon M.S. and V.A. Tucker. 1965. Osmotic regulation in the tadpoles of the crab-eating frog (Rana cancrivora). J Exp Biol 42:437-445.

Gosner K.L. 1960. A simplified table for staging anuran embryos and larvae with notes on identification. Herpetologica 16:183-190.

Hayes T.B. 1995. Interdependence of corticosterone and thyroid hormones in larval toads (Bufo boreas). I. Thyroid hormonedependent and independent effects of corticosterone on growth and development. J Exp Zool 271:95-102.
Hayes T.B. and T.H. Wu. 1995. Role of corticosterone in amphibian metamorphosis and potential role in stress-induced metamorphosis. Neth J Zool 45:107-109.

Hoffman J. and U. Katz. 1997. Salt and water balance in the toad Bufo viridis during recovery from two different osmotically stressful conditions. Comp Biochem Physiol 117A: 147-154.

Hoffmann A.A. and P.A. Parsons. 1991. Evolutionary Genetics and Environmental Stress. Oxford University Press, Oxford.

Jones R.M. 1980. Nitrogen excretion by Scaphiopus tadpoles in ephemeral ponds. Physiol Zool 53:26-31.

Kaltenbach J.C. 1996. Endocrinology of amphibian metamorphosis. Pp. 403-431 in L.I. Gilbert, J.R. Tata, and B.G. Atkinson, eds. Metamorphosis: Postembryonic Reprogramming of Gene Expression in Amphibian and Insect Cells. Academic Press, San Diego, Calif.

Katz U. 1973. Studies on the adaptation of the toad, Bufo viridis to high salinities: oxygen consumption, plasma concentration and water content of the tissues. J Exp Biol 58:785-796.

1975. Salt induced changes in sodium transport across the skin of the euryhaline toad, Bufo viridis. J Physiol 247: 537-550.

1989. Strategies of adaptation to osmotic stress in anuran amphibia under salt and burrowing conditions. Comp Biochem Physiol 93A:499-503.

Kirschner L.B., T. Kerstetter, D. Porter, and R.H. Alvarado. 1971. Adaptation of larval Ambystoma tigrinum to concentrated environments. Am J Physiol 220:1814-1819.

Koehn R.K. and B.L. Bayne. 1989. Towards a physiological and genetical understanding of the energetics of the stress response. Biol J Linn Soc 37:157-171.

McBean R.L. and L. Goldstein. 1970. Accelerated synthesis of urea in Xenopus laevis during osmotic stress. Am J Physiol 219:1124-1130.

Neill W.T. 1958. The occurrence of amphibians and reptiles in saltwater areas, and a bibliography. Bull Mar Sci 8:1-97.

Niinuma K., M. Tagawa, T. Hirano, and S. Kikuyama. 1991. Changes in tissue concentrations of thyroid-hormones in metamorphosing toad larvae. Zool Sci 8:345-350.

Plaut I. 2000. Resting metabolic rate, critical swimming speed and routine activity of the euryhaline cyprinodontid, Aphanius dispar, acclimated to a wide range of salinities. Physiol Biochem Zool 73:590-596.

SAS Institute. 1999. SAS/STAT Software User's Guide. Release 8.00. SAS Institute, Cary, N.C.

Shi Y.-B. 2000. Amphibian Metamorphosis. Wiley, Chichester. Shoemaker V.H., S.S. Hillman, S.D. Hillyard, D.C. Jackson, L. McClanahan, P.C. Withers, and M.L. Wygoda. 1992. Exchange of water, ions, and respiratory gases in terrestrial amphibians. Pp. 81-124 in M.E. Feder and W.W. Burggren, eds. Environmental Physiology of Amphibians. University of Chicago Press, Chicago. 
Shoemaker V.H. and K.A. Nagy. 1977. Osmoregulation in amphibian and reptiles. Annu Rev Physiol 39:449-471.

Shpun S., J. Hoffman, and U. Katz. 1992. Anuran amphibia which are not acclimable to high salt, tolerate high plasma urea. Comp Biochem Physiol 103A:473-477.

Shpun S. and U. Katz. 1999. Renal response of an euryhaline toad (Bufo viridis) to acute immersion in tap water, $\mathrm{NaCl}$, or urea solutions. Physiol Biochem Zool 72:227-237.

Sinsch U., R. Seine, and N. Sherif. 1992. Seasonal changes in the tolerance of osmotic stress in natterjack toads (Bufo calamita). Comp Biochem Physiol 101A:353-360.

Stengel U. and W. Hanke. 1990. Hormonal regulation of $\mathrm{Ca}^{++}$ uptake and distribution in Xenopus laevis. Pp. 357-370 in W. Hanke, ed. Biology and Physiology of Amphibians. Fischer, Stuttgart.

Tejedo M. and R. Reques. 1997. Bufo calamita. Pp. 155-157 in J.M. Pleguezuelos, ed. Distribución y Biogeografía de los Anfibios y Reptiles de España y Portugal. Universidad de Granada, Asociación Herpetológica Española, Granada.

Uchiyama M., T. Ogasawara, T. Hirano, S. Kikuyama, and Y. Sasayama. 1990. Serum and urine osmolyte concentrations during acclimation to various dilutions of seawater in the crab-eating frog, Rana cancrivora. Zool Sci 7:967-971.
Uchiyama M. and H. Yoshizawa. 1992. Salinity tolerance and structure of external and internal gills in tadpoles of the crabeating frog, Rana cancrivora. Cell Tissue Res 267:35-44.

Ultsch G.R., D.F. Bradford, and J. Freda. 1999. Physiology: coping with the environment. Pp. 189-214 in R.W. McDiarmid and R. Altig, eds. Tadpoles: The Biology of Anuran Larvae. University of Chicago Press, Chicago.

Weber G.M., E.S. Farrar, C.K.F. Tom, and E.G. Grau. 1994. Changes in whole-body thyroxine and triiodothyronine concentrations and total content during early development and metamorphosis of the toad Bufo marinus. Gen Comp Endocrinol 94:62-71.

White B.A. and C.S. Nicoll. 1981. Hormonal control of amphibian metamorphosis. Pp. 363-396 in L.I. Gilbert and E. Frieden, eds. Metamorphosis: A Problem in Developmental Biology. Plenum, New York and London.

Wright P.M. and P.A. Wright. 1996. Nitrogen metabolism and excretion in bullfrog (Rana catesbeiana) tadpoles and adults exposed to elevated environmental ammonia levels. Physiol Zool 69:1057-1078.

Zamorano B. and A. Salibián. 1994. Ionic net fluxes through the in situ epithelia of larval Caudiverbera caudiverbera (Anura, Leptodactylidae). Alytes 12:135-144. 